\title{
Lost in Translation: Allometric scaling of bioactive dietary n-3 and n-6 fatty acids
}

\author{
Jay Whelan
}

Department of Nutrition and the Agricultural Experiment Station, University of Tennessee, Knoxville, TN 37996, USA

Corresponding Author: Jay Whelan, PhD, Professor and Head, Department of Nutrition, University of Tennessee, Knoxville, TN, 37996, USA.

Submission Date: February $27^{\text {th }}, 2017$, Acceptance Date: May $27^{\text {th }}$, 2017, Publication Date: May $30^{\text {th }}, 2017$

Citation: Whelan J. Lost in Translation: Allometric scaling of bioactive dietary n-3 and n-6 fatty acids. Functional Foods in Health and Disease 2017; 7(5); 314-328.

\begin{abstract}
Experimental animal models are the primary tool to test nutritional intervention strategies for health promotion and prevention and/or treatment of human diseases. These kinds of experiments test hypotheses that otherwise could not be done in humans. These models generate data important for pre-clinical screening purposes. However, their ability to predict human responses has been disappointing, particularly when it comes to dietary n-3 and n-6 polyunsaturated fatty acids (PUFA). Many times, it is difficult to recapitulate the data as a result of diet between pre-clinical experiments and clinical trials, in part because we lack the fundamental understanding of how to effectively translate diets between species. The diets in experiments using rodent models are preferentially designed to generate positive results (i.e., perform a dose response and pick the dose that works) with little thought on their applicability to humans. Accordingly, the levels of n-3 and n-6 PUFA used in rodent diets are typically on the extreme and rarely justified. A search of the literature reveals no guidelines establishing appropriate levels for the use of PUFA in rodent diets, although extrapolation to human conditions is quite common despite being inappropriate. The goal of this paper is to examine allometric scaling models between species for dietary PUFA using similar endpoints with the hypothesis that equivalent physiological changes in rodents and humans support the mathematical model.
\end{abstract}

Keywords: alpha-linolenic acid, allometric scaling, arachidonic acid, docosahexaenoic acid, eicosapentaenoic acid, linoleic acid, n-6, n-3, plasma fatty acids, polyunsaturated fatty acids

\section{INTRODUCTION:}

The relationship of diet and disease finds its foothold with basic research using pre-clinical experimental models (i.e., rodents). It is fundamentally important to generate positive results in these models as a stepping-stone to clinical trials. However, to accomplish this adequately, rodent diets need to be compatible with human diets to enhance our abilities to translate physiological outcomes between species. Furthermore, the elucidation of underlying mechanisms 
using these models (which is difficult to do in humans) is critical in understanding the dietdisease relationships.

The physiological functions of polyenoic lipids have been extensively studied since the discovery of essential fatty acids $[1,2]$. Over the intervening decades, their nutritional benefits have been expanded from their roles as structural components of cellular membranes to other roles in cell signaling, health, and disease. Two families of polyunsaturated fatty acids (PUFA) have predominated the literature over the last 50 years, the n-3 and n-6 PUFA. The importance of these two polyunsaturated fatty acids in acute and chronic diseases cannot be overstated. Accordingly, our ability to explore their physiological effects in rodent models and apply this information to humans requires our ability to translate exposure from one species to another.

\section{N-6 AND N-3 POLYUNSTURATED FATTY ACIDS AND THEIR METABOLISM}

There are two major families of PUFA, the n- 6 and n-3 families. Placement of their double bonds are at three carbon intervals, with cis configurations, at similar locations in fatty acids of the same carbon length regardless of family (Fig. 1). The only difference is the location of the initial double bond from the methyl end. PUFA in the n-3 family have a double bond 3 carbons from the methyl end, while PUFA from the n- 6 family do not possess the double bond at carbon 3 from the methyl end. Therefore, the first double bond begins at the $6^{\text {th }}$ carbon. Because mammals do not have the capacity to insert double bonds beyond the $9^{\text {th }}$ carbon from the carbonyl end, n- 6 and n-3 PUFAs are not metabolically interconvertible.

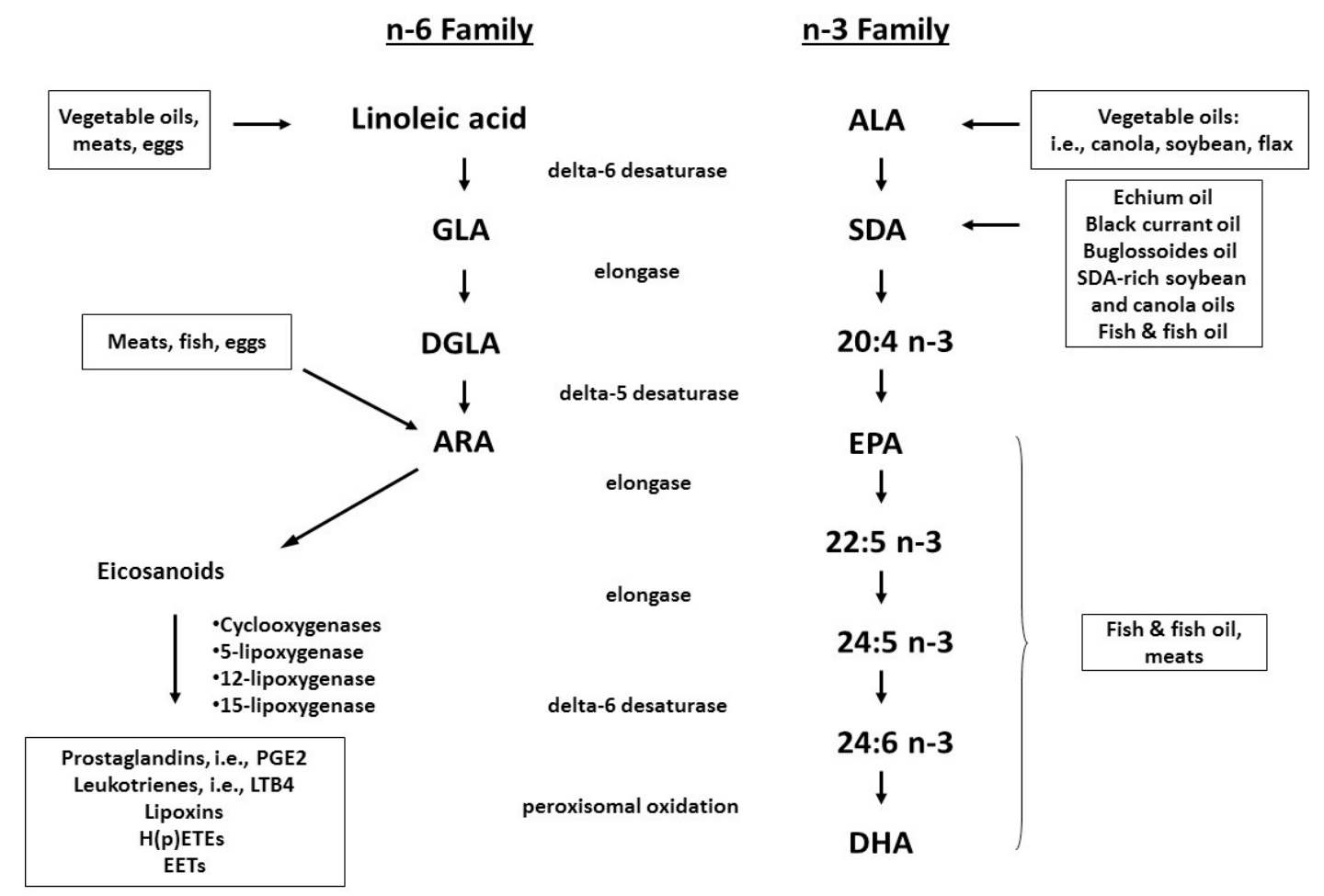

Figure 1. Metabolic pathways for $n-6$ and n-3 polyunsaturated fatty acids. Abbreviations: ARA, arachidonic acid; ALA, alpha linolenic acid; DGLA, dihomo-gamma-linolenic acid; DHA, docosahexaenoic acid; DPA, docosapentaenoic acid; EPA, eicosapentaenoic acid; ETA, eicosatetraenoic acid; LA, linoleic acid; GLA, gamma linolenic acid; SDA, stearidonic acid (as published previously [3]). 
Linoleic (18:2 $\mathrm{n}-6, \mathrm{LA})$ is the major PUFA in the diet $(12 \mathrm{~g} / \mathrm{d}-17 \mathrm{~g} / \mathrm{d} ; \sim 6 \%$ of energy) and is the parent compound for the rest of the n-6 PUFA family [4]. Arachidonic acid (20:4 n-6, ARA; $170-200 \mathrm{mg} / \mathrm{d} ; \sim 0.07 \%$ energy), arguably the most important PUFA associated with membrane phospholipids, is a downstream metabolite of LA. If there is a dietary deficiency in n-6 PUFA, supplementation of LA will restore tissue levels of ARA.

Alpha-linolenic acid (ALA, $1.1 \mathrm{~g} / \mathrm{d}-1.6 \mathrm{~g} / \mathrm{d} ; \sim 0.65 \%$ energy) is the parent fatty acid for the n-3 family of fatty acids. This essential fatty acid is rapidly and efficiently elongated and desaturated to the more biologically active eicosapentaenoic acid (20:5 n-3, EPA) and docosahexaenoic fatty acid (22:6 n-3, DHA) under conditions of insufficiency. DHA is the preferred metabolic endpoint. Dietary amounts of EPA+DHA are estimated to be $\sim 200 \mathrm{mg} / \mathrm{d}$ $(\sim 0.10 \%$ energy) and are potent antagonists of ARA.

A major concern with regards to dietary n-6 PUFA, in particular LA, is their potential conversion to ARA. The levels of ARA in the tissues are significantly correlated with the production of a variety of bioactive eicosanoids [5]. When produced chronically and at elevated levels, these compounds have been associated with chronic diseases, including cardiovascular disease (CVD) [6, 7], cancer [8, 9], and inflammatory disorders [10], raising concerns about the health effects of n-6 PUFA, in particular LA and ARA.

On the other hand, n-3 PUFA, particularly those found in fish and fish oil (e.g., EPA and DHA), interfere with the metabolism of arachidonic acid by acting as competitors of enzymes associated with the arachidonic acid cascade. Many of the beneficial effects of n-3 PUFA have been attributed to their ability to antagonize ARA signaling. When investigating the health impacts of n-6 and n-3 PUFA, it is critical to establish reliable mechanisms that can be translated to humans. Frequently, this is left to pre-clinical models and is dependent upon appropriate rodent diets and allometric scaling.

The goal of this paper is to investigate a mathematical model for the allometric scaling of dietary PUFA between mice and humans using similar endpoints, with the hypothesis that equivalent physiological changes support the use of the mathematical model.

\section{ALLOMETRIC SCALING MODELS}

There are two major mathematical models typically used for allometric scaling of nutrients between species: body weight in kilograms $\left(\mathrm{BW}_{\mathrm{kg}}\right)$ and some aspect of metabolic rate (MR) based on the relationship of energy expenditure and body surface area, the latter of which is described in the equation: $k_{(\text {constant })}\left(\mathrm{BW}_{\mathrm{kg}}\right)^{x}$, where $k$ is a constant for a particular species and $x$ is an exponent that falls between 0.6 and $0.8[11,12]$.

Body weight: Extrapolations based on body weight are mathematically simple, easy to use and relatively uniform between species. For example, the weight of mice typically ranges between $15-40 \mathrm{~g}$, while humans are more than two orders of magnitude heavier (typically, 50-120 kg). The major drawback with using the difference in body weight is that there is a linear relationship trying to normalize a non-linear phenomenon (nutrient requirement between species, as described previously [11]). For example, the conversion factor for a C57BL/6 mouse that weighs $25 \mathrm{~g}$ to a human that weighs $70 \mathrm{~kg}$ is 2800 . If a mouse consumed $4.6 \mathrm{~g} / \mathrm{d}$ of AIN76A diet, it would be consuming a dose of LA of $0.14 \mathrm{~g} / \mathrm{d}$ (AIN76A contains $5 \%$ corn oil (w/w), of which LA is $60 \%$ ). Based upon extrapolation of $\mathrm{BW}$, the rodent is consuming a human equivalent dose of $386 \mathrm{~g} /$ day. Extrapolating intakes in the other direction, from humans to mice, the mouse would become essential fatty acid deficient (e.g., $15 \mathrm{~g} \mathrm{LA} / \mathrm{d}$ for humans divided by $2800=$ $0.0054 \mathrm{~g} / \mathrm{d}$ for a mouse). Clearly, allometric scaling of essential fatty acids using differences in 
BW results in an over-estimation when extrapolating from mice to humans, and an underestimation when the extrapolation is in the other direction (humans to mice).

Metabolic rate: Extrapolations of nutrients based on metabolism have their origins with those who originally investigated mathematical models that linearized basal metabolic rate between species of different sizes (as reviewed by Rucker [12]). Body surface area was an important consideration in the generation of these formulas, as metabolic rate is proportional to body surface area (known as the Surface Law) [13]. These formulas were designed to mathematically explain this relationship, where Kleiber (1947) proposed the following formula for mammals and birds:

$$
M=70.4(B W)^{0.75}
$$

where $M$ was the metabolic rate in kilocalories, $B W$ is body mass in kilograms. At the time, 0.75 selected as an approximation because it could easily be used with a slide ruler (an earlier version of a hand-held calculator) [13]. Others suggested that the basal metabolic rate based on body surface area was better defined using 0.67 as the exponent [14]. These formulas were designed to explain the relationship between metabolic rate and body size, but not nutrient intake. However, it was proposed that food components and essential nutrients could also be expressed in terms of "metabolic body size" [13]. This concept was used to develop a formula for nutrient extrapolations between species based on body surface area [15]:

Human Equivalent Dose $(\mathrm{mg} / \mathrm{BW})=$ Animal dose $(\mathrm{mg} / \mathrm{BW})($ Animal $\mathrm{Km}) /(\operatorname{Human} \mathrm{Km})$

where $\mathrm{mg}$ is the daily intake of a nutrient, BW is body mass in kilograms, and $\mathrm{Km}$ is a speciesdependent multiplication factor ( $\mathrm{Km}$ for a mouse is 3, and $\mathrm{Km}$ for an adult human is 37). This formula was derived from a 2002 report published by the Food and Drug Administration [16], which was based in part on the earlier work of Freireich et al. (1966) [17]. This formula utilized body surface area and was originally designed as a tool to determine safe doses for new chemotherapeutic agents based on a percent of the lethal dose $(10 \%)$ in preclinical models (as delivered intraperitoneally) compared with the maximum tolerable dose in human patients (provided intravenously).

In 2002, Rucker and colleagues proposed that the extrapolation of nutrients (vitamins and minerals) between species could be scaled based on energy needs [11, 18]:

"We suggest that when making interspecies comparisons from a nutrition perspective, the strongest case is made when a measure of metabolic body size or food intake, rather than body weight, is used to extrapolate the dosages required for a given response" [11].

Based on this work, we compared the different allometric models for the scaling of essential nutrients from standardized rodent diets (i.e., AIN76A, AIN93G and AIN93M) with human recommendations as outlined by the Dietary Reference Intakes (DRI) (Table 1) [19].

These data demonstrate that extrapolating the levels of dietary PUFA (LA and ALA) in the various rodent diets matched most closely with the DRIs when allometrically scaled using the "metabolic rate".

Furthermore, similar results were observed when the same scaling methods were used with the micronutrients, where scaling based on metabolic rate best matched the US DRI values when compared to using body weight, body surface area $\left(\mathrm{BW}^{0.67}\right)$, or the formula outlined above [15]. It should be pointed out that the nutrient compositions recommended for the AIN76A, AIN93G, and AIN93M diets are based on the fundamental physiological needs of the animals, or that they were originally formulated to adequately support growth, reproduction, and lactation (with 
AIN93G and AIN93M diets being improvements to the AIN76A diet) [20, 21]. This is not unlike the DRI recommendations proposed by the Institute of Medicine [19], where nutrient recommendations are designed to maintain health in a normal population.

These comparisons provided the rationale for testing interspecies scaling of dietary PUFA using metabolic rate as the converting factor with an endpoint of changes in tissue fatty acid composition. This outcome measure was used because it reflects physiological function and there is sufficient human data for appropriate interspecies comparisons.

Table 1. Human equivalent doses of micro- and macronutrients in AIN76A, AIN93G, and AIN93M diets as converted by different formulas and compared to the US DRI.

\begin{tabular}{|c|c|c|c|c|c|c|c|c|c|c|c|c|c|}
\hline \multirow[t]{2}{*}{ Nutrient } & \multirow[b]{2}{*}{ US DRI } & \multicolumn{4}{|c|}{ AIN76A diet } & \multicolumn{4}{|c|}{ AIN93G diet } & \multicolumn{4}{|c|}{ AIN93M diet } \\
\hline & & Metabolic Rate & $\mathrm{BW}_{(\mathrm{Kg})}$ & Formula & BSA & Metabolic Rate & $\mathrm{BW}_{(\mathrm{Kg})}$ & Formula & BSA & Metabolic Rate & $\mathrm{BW}_{(\mathrm{Kg})}$ & Formula & BSA \\
\hline Linoleic Acid & $12 \mathrm{~g}-17 \mathrm{~g}$ & 18 & 386 & 31 & 28 & 21 & 442 & 36 & 32 & 12 & 253 & 20 & 18 \\
\hline a-Linolenic Acid & $1.1 \mathrm{~g}-1.6 \mathrm{~g}$ & 0.0 & 0 & 0 & 0 & 2.7 & 57 & 4.6 & 4.2 & 1.6 & 33 & 2.7 & 2.4 \\
\hline Thiamin & $1.2 \mathrm{mg}$ & 3.3 & 69 & 6 & 4 & 2.7 & 56 & 5 & 4 & 2.8 & 59 & 5 & 4 \\
\hline Riboflavin & $1.3 \mathrm{mg}$ & 3.7 & 77 & 6 & 5 & 3.2 & 67 & 5 & 5 & 3.3 & 70 & 6 & 5 \\
\hline B6 & $1.3 \mathrm{mg}$ & 3.5 & 74 & 6 & 5 & 3.2 & 67 & 5 & 5 & 3.3 & 70 & 6 & 5 \\
\hline Niacin & $16 \mathrm{mg}$ & 18 & 386 & 31 & 24 & 16 & 336 & 27 & 24 & 17 & 351 & 28 & 26 \\
\hline folate & $400 \mu \mathrm{g}$ & 1227 & 25760 & 2089 & 1632 & 1067 & 22400 & 1816 & 1632 & 1115 & 23408 & 1898 & 1705 \\
\hline Biotin & $30 \mu \mathrm{g}$ & 123 & 2576 & 209 & 163 & 107 & 2240 & 182 & 163 & 111 & 2341 & 190 & 171 \\
\hline Vit E & $15 \mathrm{mg}$ & 21 & 451 & 37 & 29 & 27 & 560 & 45 & 41 & 28 & 585 & 47 & 43 \\
\hline Vit D & $5 \mathrm{mg}$ & 15 & 322 & 26 & 20 & 13 & 280 & 23 & 20 & 14 & 293 & 24 & 21 \\
\hline Vit A & $900 \mu \mathrm{g}$ & 736 & 15456 & 1253 & 979 & 640 & 13440 & 1090 & 979 & 669 & 14045 & 1139 & 1023 \\
\hline Vit C & $90 \mathrm{mg}$ & 0 & 0 & 0 & 0 & 0 & 0 & 0 & 0 & 0 & 0 & 0 & 0 \\
\hline Vit K & $120 \mu \mathrm{g}$ & 31 & 644 & 52 & 41 & 480 & 10080 & 817 & 734 & 479 & 10065 & 816 & 733 \\
\hline B12 & $2.4 \mu \mathrm{g}$ & 6 & 129 & 10 & 8 & 13 & 280 & 23 & 20 & 14 & 293 & 24 & 21 \\
\hline Pantothenate & $5 \mathrm{mg}$ & 9 & 189 & 15 & 12 & 8 & 168 & 14 & 12 & 8 & 176 & 14 & 13 \\
\hline $\mathrm{Ca}$ & $1000 \mathrm{mg}$ & 3189 & 66976 & 5430 & 4243 & 2667 & 56000 & 4541 & 4080 & 2787 & 58520 & 4745 & 4264 \\
\hline $\mathbf{P}$ & $700 \mathrm{mg}$ & 2453 & 51520 & 4177 & 3264 & 1600 & 33600 & 2724 & 2448 & 1672 & 35112 & 2847 & 2558 \\
\hline K & $4700 \mathrm{mg}$ & 2208 & 46368 & 3760 & 2938 & 1920 & 40320 & 3269 & 2938 & 2006 & 42134 & 3416 & 3070 \\
\hline $\mathrm{Na}$ & $1500 \mathrm{mg}$ & 626 & 13138 & 1065 & 832 & 551 & 11570 & 938 & 843 & 576 & 12090 & 980 & 881 \\
\hline $\mathrm{Cl}$ & $2300 \mathrm{mg}$ & 957 & 20093 & 1629 & 1273 & 870 & 18267 & 1481 & 1331 & 899 & 18879 & 1531 & 1375 \\
\hline $\mathrm{Mg}$ & $400 \mathrm{mg}$ & 307 & 6440 & 522 & 408 & 274 & 5746 & 466 & 419 & 285 & 5981 & 485 & 436 \\
\hline$S$ & NA & 613 & 12880 & 1044 & 816 & 160 & 3360 & 272 & 245 & 167 & 3511 & 285 & 256 \\
\hline $\mathrm{Cr}$ & $35 \mu \mathrm{g}$ & 1227 & 25760 & 2089 & 1632 & 533 & 11200 & 908 & 816 & 557 & 11704 & 949 & 853 \\
\hline $\mathrm{Cu}$ & 900 ug & 3680 & 77280 & 6266 & 4896 & 3200 & 67200 & 5449 & 4896 & 3344 & 70224 & 5694 & 5116 \\
\hline FI & $4 \mathrm{mg}$ & 0 & 0 & 0 & 0 & 1 & 11 & 1 & 1 & 1 & 12 & 1 & 1 \\
\hline I & $150 \mu \mathrm{g}$ & 123 & 2576 & 209 & 163 & 107 & 2240 & 182 & 163 & 111 & 2341 & 190 & 171 \\
\hline $\mathrm{Fe}$ & $8 \mathrm{mg}$ & 21 & 451 & 37 & 28.6 & 24 & 504 & 41 & 37 & 25 & 527 & 43 & 38 \\
\hline $\mathrm{Mn}$ & $2.3 \mathrm{mg}$ & 33 & 696 & 56 & 44 & 5 & 112 & 9 & 8 & 6 & 117 & 9 & 9 \\
\hline Mo & $45 \mu \mathrm{g}$ & 0 & 0 & 0 & 0 & 80 & 1680 & 136 & 122 & 84 & 1756 & 142 & 128 \\
\hline Se & $55 \mu \mathrm{g}$ & 61 & 1288 & 104 & 82 & 96 & 2016 & 163 & 147 & 95 & 1990 & 161 & 145 \\
\hline $\mathrm{Zn}$ & $11 \mathrm{mg}$ & 18 & 386 & 31 & 24 & 20 & 426 & 35 & 31 & 20 & 410 & 33 & 30 \\
\hline
\end{tabular}

Nutrients were extrapolated based on metabolic rate in calories $(15 \mathrm{Kcal} / \mathrm{d}$ for a mouse and $2000 \mathrm{Kcal} / \mathrm{d}$ for a human), body weight (BW: $0.025 \mathrm{Kg}$ for a mouse and $70 \mathrm{Kg}$ for a human), the formula [15]: [Human Equivalent Dose $(\mathrm{mg} / \mathrm{BW})=$ Animal dose $(\mathrm{mg} / \mathrm{BW})($ Animal $\mathrm{Km}) /($ Human $\mathrm{Km})]$ or body surface area (BSA) using the formula $\left(\mathrm{BW}_{\mathrm{kg}}\right)^{0.67}$. Abbreviation: DRI, Dietary Reference Intakes.

\section{CURRENT PROBLEMS WITH EXPERIEMNTAL DESIGNS}

There are four major problems in literature with regards to designing rodent diets when evaluating the impact of n-3 and n-6 PUFAon health outcomes using pre-clinical experimental animal models.

1. When studying the effects of n-3 PUFA, it is common to eliminate all n-3 PUFA in the background/control diet to control for "confounding". This is typically done by using a control diet devoid of n-3 PUFA. For example, a common control diet that is used is the 
AIN76A diet contains 5\% corn oil as the lipid source. The rationale for this is logical. Any changes as a result of supplementation of n-3 PUFA, in place of corn oil, can reasonably be attributed to the addition of the n-3 PUFA. Many of the effects of dietary PU FA have found their roots in the classic studies by Mohrhauer and Holman (1963), who supplemented fat-free rodent diets various doses of a variety of PUFA and evaluated their effects on tissue fatty acid composition [22-24].

2. The second problem deals with other PUFA that may or may not be included in the background/control diet because these PUFA can influence the results. For example, with the exception of vegans (individuals who do not eat or use animal products), the human background diet contains highly unsaturated fatty acids in the form of ARA, EPA, and DHA, but the rodent background/control diet rarely contains these fatty acids. The most common semi-purified diets used in rodent experiments are AIN76A, AIN93G, and AIN93M and the lipid fractions are derived from either corn oil or soybean oil. The only PUFA in these diets are ALA and/or LA. "Chow" diets typically contain soybean oil as the lipid source, but the lipid source and amount can vary.

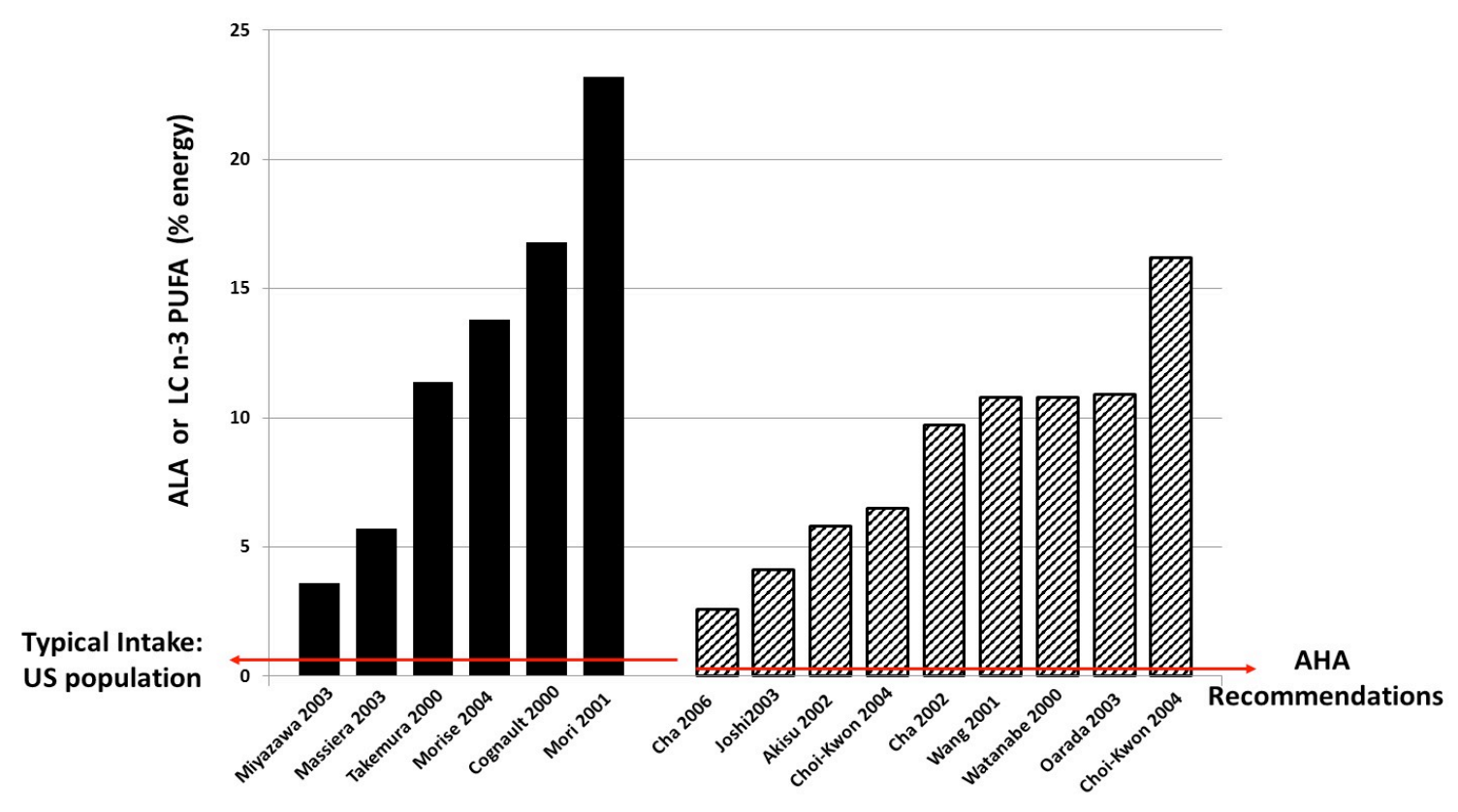

Figure 2. Selected papers where alpha-linolenic acid (ALA) (solid bars) or long chain (LC) n-3 PUFA (hatched bars) were supplemented to rodents on corn oil-based diets. Amounts supplemented are based on \% energy in the diet. For reference, the typical intake in the US population for ALA and the American Heart Association (AHA) recommendations for LC n-3 PUFA are presented (based on $\%$ energy).

3. The third problem resides in the doses used. The diets of rodents are designed to generate "positive" results, not to investigate whether the results have translatability. Accordingly, diets are supplemented with exorbitant amounts (pharmacological doses) of the PUFA of interest (i.e., pharmacological doses of n-3 PUFA to a background diet devoid of n-3 PUFA). This occurrence is summarized in randomly selected papers where the investigators supplemented ALA and long chain (LC) n-3 PUFA to n-3 deficient diets at levels as high as $23 \%$ of energy (\%en) and $16 \%$ en respectively (Fig. 2). This compares to typical US intakes of $0.63 \%$ en for ALA and $0.1 \%$ en for LC n-3 PUFA[19], or the 
recommended intakes of $0.23 \mathrm{en} \%$ for EPA+DHA by the American Heart Association (AHA) ( $\sim 500 \mathrm{mg} / \mathrm{d})$ [25]. Sometimes dose-response curves are generated, with the dose that has a significant impact being selected for further study. Rarely are levels selected based on human equivalent doses.

4. Finally, the rodent model itself creates a challenge. The composition of DHA in a variety of tissues (heart, skeletal muscle, liver, kidney) decreases as body size increases, even though the total number of unsaturated fatty acids in the tissues remain constant (the noted exception, the brain, where DHA levels remain constant regardless of body size) [26]. This decrease is primarily related to compensation by monounsaturated fatty acids (increase), as the n-6 PUFA content remains relatively constant. These effects correlate with metabolism, suggesting the higher metabolic rates of small rodents influence the elongation and desaturation of precursor n-3 PUFA to a greater extent compared with humans. This means that dietary ALA and EPA will have a greater impact on changing tissue DHA levels in rodents depending upon levels of PUFA in the background diet.

\section{WHAT IS KNOWN ABOUT THE IMPACT OF DIETARY PUFA ON LEVELS OF TISSUE PUFA IN HUMANS?}

A systematic review of the human literature revealed that changes in dietary LA has relatively little impact on tissue ARA levels, regardless of the amount supplemented or withdrawn [27]. This contradicts many unsubstantiated claims that tissue ARA content and its downstream metabolites are positively influenced by dietary LA (as reviewed in [27]). Similarly, supplemented levels of dietary ALA on top of a typical Western diethave no effect on the tissue levels of DHA, and only begin to have effects on changing EPA levels when supplemented to the diet at doses greater than $3 \mathrm{~g} / \mathrm{d}[3,28]$. This data suggests that if you want to significantly influence tissue levels of EPA, one would have to consume ALA at doses beginning at $\sim 4.4 \mathrm{~g} / \mathrm{d}$ (typical intake of $1.4 \mathrm{~g} / \mathrm{d}+$ supplementation of $3 \mathrm{~g} / \mathrm{d}$ ). Because the rate-limiting step in DHA formation (delta-6 desaturase) is inhibited under conditions of a Western diet, even the consumption of EPA fails to influence tissue levels of DHA [3, 28].

Arachidonic acid is a PUFA that is only found in animal products, primarily animal tissue (terrestrial meats and organs, fish and eggs) [29]. When consumed, the ARA content of tissues increases. Significantly, this incorporation is at the direct expense of LA [30]. Accordingly, dietary ARA and tissue levels of LA have an inverse relationship.

If the dietary design of pre-clinical models (i.e., rodents) is to be translated to humans, certain criteria should be met based on outcomes that are comparable between species, in this case, changes in tissue fatty acid composition. For translation, the following effects should occur when the underlying background diet (control diet) is supplemented with the PUFA of interest (experimental diet).

1. Following supplementation of ALA to the diet, tissue DHA levels shouldn't change.

2. Following supplementation of EPA to the diet, tissue DHA levels shouldn't change.

3. Following supplementation/removal of LA to/from the diet, tissue ARA levels shouldn't change.

4. Following supplementation of ARA to the diet, tissue LA levels should be reduced in a dose-dependent manner.

If any of these criteria are not satisfied, the dietary design lacks translatability. 


\section{ALLOMETRIC SCALING OF DIETARY PUFA BETWEEN MICE AND HUMANS BASED ON METABOLIC RATE}

Critical to this kind of study is the experimental design, specifics of which have been presented in detail elsewhere [27, 31]. Briefly, the rodent diets (Research Diets, New Brunswick, NJ) were designed to mimic the recommendations for the US diet (DRIs) using the following energy distribution of macronutrients: lipids at $34 \%$ en, proteins at $16 \%$ en, and carbohydrates at $50 \%$ en (Table 2). In regards to the dietary lipids, the rodent diets mimicked the distribution of saturated $(13 \%$ en), monounsaturated (14\%en), and polyunsaturated fats $(\sim 7 \%$ en) (Table 2$)$. The PUFA in the control diet were also provided at levels equivalent to those in the US diet with the following distribution: LA $(6.3 \% \mathrm{en})$, ARA $(0.07 \% \mathrm{en})$, EPA+DHA $(0.1 \% \mathrm{en})$, and two different doses of ALA $(0.65 \%$ en and $1.3 \% \mathrm{en})$. The human equivalent levels for these fatty acids corresponded to daily intakes of $14 \mathrm{~g} / \mathrm{d}$ for LA, $156 \mathrm{mg} / \mathrm{d}$ for ARA, $200 \mathrm{mg} / \mathrm{d}$ for EPA+DHA, and $1.4 \mathrm{~g} / \mathrm{d}$ or 2.8 $\mathrm{g} / \mathrm{d}$ for ALA, for an individual consuming 2000 kilocalories/d. These background diets represented the lipid distribution of a typical American diet. To this diet, various PUFA (i.e., LA, ALA, ARA, or EPA) were added or subtracted to mimic supplementation or reduction in a similar manner where an individual might modify their dietary intakes.

Table 2. Dietary design of the background diet of the mice as compared to the US diet (components are presented as \% of energy).

\begin{tabular}{llllll}
\hline \multicolumn{3}{c}{ Macronutrients (\% energy) } & \multicolumn{2}{c}{ Polyunsaturated Fatty Acids (\% energy) } \\
& US & Rodent & & US & Rodent \\
Protein & 16 & 16 & $18: 2 \mathrm{n}-6$ & 6.3 & 6.3 \\
Carbohydrate & 50 & 50 & $18: 3 \mathrm{n}-3$ & 0.63 & 0.65 or 1.3 \\
Lipids & 34 & 34 & $20: 4 \mathrm{n}-6$ & 0.07 & 0.07 \\
$\quad$ SFA & 13 & 13 & $20: 5 \mathrm{n}-3$ & 0.034 & 0.034 \\
MUFA & 14 & 14 & $22: 6 \mathrm{n}-3$ & 0.054 & 0.054 \\
PUFA & 7 & 7 & & &
\end{tabular}

Abbreviations: MUFA, monounsaturated fatty acids; PUFA, polyunsaturated fatty acids; SFA, saturated fatty acids

In studies evaluating allometric scaling of n-3 PUFA, these diets were supplemented with three doses of ALA or EPA $(0.3 \% \mathrm{en}, 0.8 \% \mathrm{en}$ and $1.4 \% \mathrm{en})$ with two background doses of ALA $(0.65 \%$ en or $1.3 \%$ en) (Table 3$)$. These two background doses were chosen because of the greater capacity of rodents to metabolize n-3 PUFA to EPA and DHA and incorporate them into tissues [26]. For the studies evaluating dietary n-6 PUFA, diets were supplemented with either LA at 5 doses (minus 2\%en, $2 \%$ en, $4 \%$ en, $6 \%$ en, and $8 \%$ en) or ARA at 3 doses $(0.23 \%$ en, $0.45 \%$ en, $1.36 \%$ en) (Table 4), with oleic acid being the control in all experiments. These levels are similar to those suggested in the literature for humans on a Western diet $[29,32,33]$ and/or supported by the DRIs for median daily intakes [19]. All diets remained isocaloric and were verified with fatty acid analysis. All mice were maintained on the control diet for one week to equilibrate the tissues (previous experiments in our lab demonstrated steady state levels of tissue fatty acids are achieved within 1 week), and then placed on the experimental diets for an additional four weeks. After that time, the animals were sacrificed and plasma and erythrocyte fatty acid compositions were determined as described previously [31]. (Note: All animal procedures were approved by the University of Tennessee Animal Care and Use Committee in accordance with NIH guidelines.)These data were then compared to similar data generated in humans participating in clinical trials [27]. For a complete list of those studies, please see references [3, 27]. 
The impact of supplementing n-3 or n-6 PUFA on changes in tissue phospholipid content in humans

N-3 PUFA Supplementation. With regards to the impact of dietary n-3 PUFA, when humans who were consuming a typical Western diet are supplemented with increasing levels of ALA, the impact on plasma phospholipid EPA concentrations can be defined with the following equation: $y=41.6 \log (x)+58.8$, where " $\mathrm{x}$ " is the level of "supplemented" ALA to the diet (\%en) and " $\mathrm{y}$ " is the change in tissue EPA content (\% change from baseline) (Fig. 3A, squares) [3].

A.

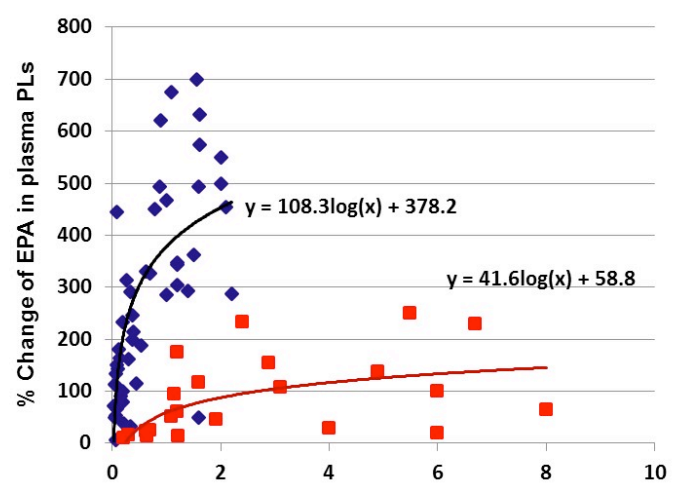

Increasing levels of dietary ALA (squares) or EPA (diamonds) (\% en)
B.

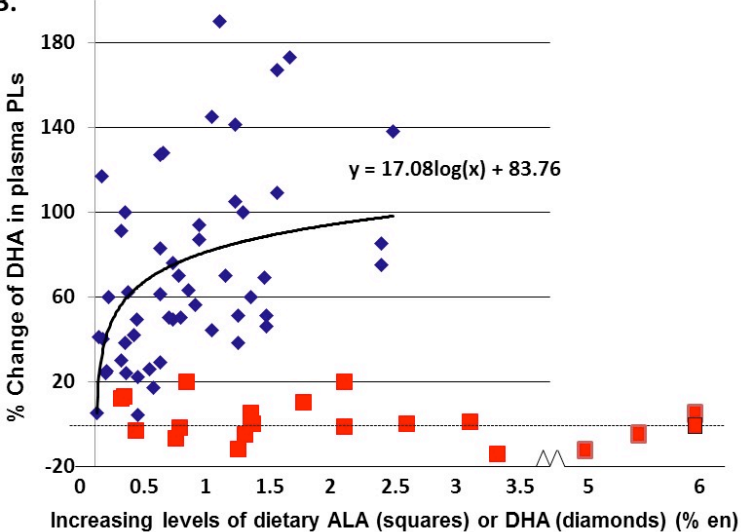

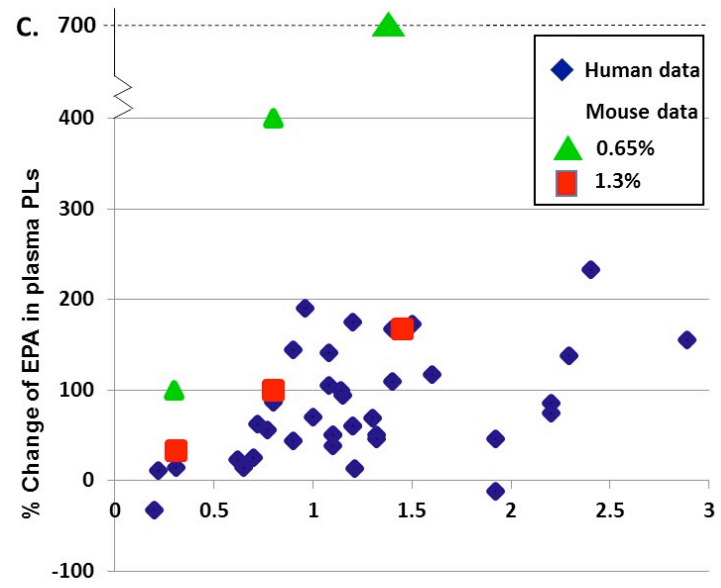

Increasing dietary levels of ALA (\% energy)

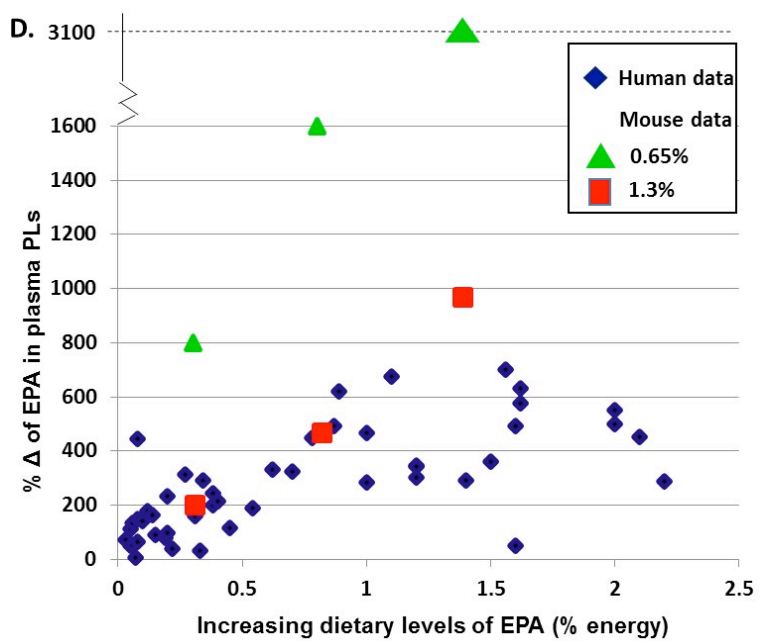

Figure 3. The effect of ALA, EPA and DHA supplementation on changes (\%) in plasma EPA and DHA phospholipid content in humans and mice consuming a typical Western diet [3]. (A) Change (\%) in plasma EPA phospholipid content in humans with increasing levels of dietary ALA (squares) or EPA (diamonds). (B) Change (\%) in plasma DHA phospholipid content in humans with increasing levels of dietary ALA (squares) or DHA (diamonds). (C) Change (\%) in plasma EPA phospholipid content with increasing levels of dietary ALA. The human data is represented with diamonds, superimposed with the results of the mouse data (background ALA at $0.65 \%$ (triangles), or 1.3\% (squares)). (D) Change (\%) in plasma EPA phospholipid content with increasing levels of dietary EPA. The human data is represented with diamonds, superimposed with the results of the mouse data (background ALA at $0.65 \%$ (triangles), or $1.3 \%$ (squares)).

When human diets were supplemented with increasing levels of EPA, the impact on plasma phospholipid EPA concentrations can be defined with the following equation: $y=108.3 \log (x)+378.2$, where " $\mathrm{x}$ " is the level of "supplemented" EPA to the diet (\%en) and " $\mathrm{y}$ " is the change in tissue EPA content (\% change from baseline) (Fig. 3A, diamonds). When increasing amounts of ALA were supplemented to the diets of individuals consuming a typical Western diet, tissue DHA levels do not change, regardless of the amount supplemented (Fig. 3 
B). Similarly, supplementation of EPA had no effect on DHA levels (as previously published in reference [3]), data that is consistent with the literature [28]. However, DHA supplementation increased plasma phospholipid DHA concentrations in a dose-dependent manner and this relationship can be defined by the following equation: $y=17.08 \log (x)+83.76$ (Fig. 3B, diamonds). Similar results were observed with changes in erythrocyte phospholipids following supplementation (data not shown).

N-6 PUFA Supplementation. With regards to the impact of dietary n-6 PUFA, when humans who are consuming a typical Western diet are supplemented with increasing or decreasing levels of LA, plasma phospholipid levels of ARA do not change, regardless of the amount supplemented (up to 600\%) or reduced (by 90\%) (Fig. 4A, diamonds). Similar results were observed with changes in erythrocyte phospholipids following supplementation [27]. However, when ARA was supplemented to diets to individuals consuming a Western diet, tissue ARA levels increased in a dose dependent manner (Fig. 4B, diamonds).

A.

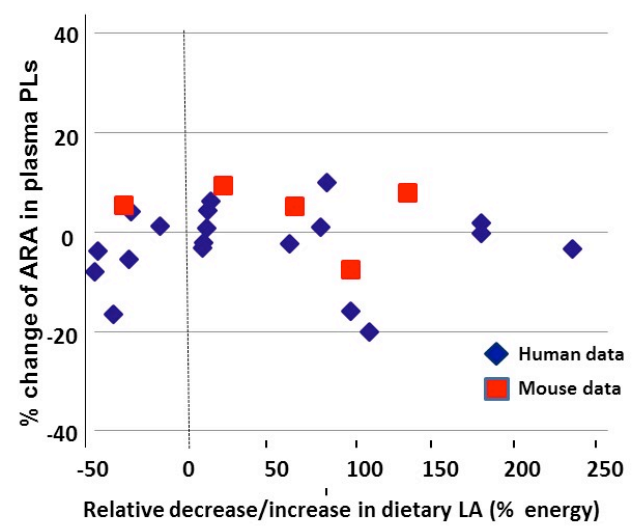

B.

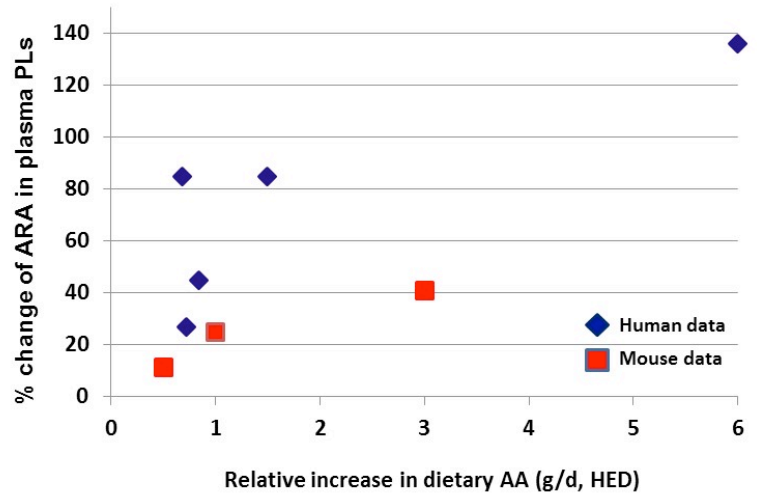

Figure 4. The effect of LA and ARA supplementation on changes (\%) in plasma ARA phospholipid content in humans consuming a typical Western diet [27]. (A) Change (\%) in plasma ARA phospholipid content with increasing levels of dietary LA. The human data is represented with diamonds, superimposed with the results of the mouse data (squares). (Note: The level of ALA in the background was $0.65 \% \mathrm{en}$ ). (B) Change (\%) in plasma ARA phospholipid content with increasing levels of dietary ARA. The human data is represented with diamonds, superimposed with the results of the mouse data (squares). (Note: The level of ALA in the background was $0.65 \%$ en).

\section{The impact of supplementing n-3 or n-6 PUFA on changes in tissue phospholipid content in mice as compared to humans}

Mouse background diets were designed to mimic the US diet as per the DRIs, based on \% energy (Table 2). They were supplemented with n-3 and n-6 PUFA at human equivalent doses (based on $\%$ energy). Changes in phospholipid fatty acids were determined, and the changes in the PUFA content of plasma and erythrocytes are presented in Tables 3 and 4 (data in Table 4 is derived from reference [31]). These data were then compared to the human data (Fig. 3C and D, and Fig. 4).

$N-3$ PUFA Supplementation. When mice, on background diets that mimicked the US diet, were supplemented with ALA, tissue responses were similar as that observed within humans at the same supplemented dose, but only when the background levels of ALA were twice that of the DRIs for ALA (i.e., $1.3 \%$ en versus $0.65 \%$ en) (Table 3, Fig. 3C). When the background diets contained ALA at a level of $0.65 \%$ en versus $1.3 \%$ en, the mouse tissues exhibited significantly 
higher changes in EPA and DHA (Table 3). It looks as if the difference is the result of the starting EPA and DHA values in the tissues of the Control animals (higher in the $1.3 \mathrm{en} \%$ diets), as there appears to be a tissue threshold for DHA following supplementation. Similar results were observed with supplementation of EPA, as the results in mice were most similar to the human data only when the background diet contained ALA at a level of $1.3 \%$ en (Fig. 3D). These results also appear to be related to the differences in the Control tissues following supplementation of ALA at $0.65 \%$ en or $1.3 \%$ en (Table 3 ). As observed with ALA, there appeared to be a response threshold for DHA following EPA supplementation (Table 3).

Table 3. The effects of ALA or EPA supplementation on plasma or erythrocyte n-3 PUFA composition in mice.

\begin{tabular}{|c|c|c|c|c|}
\hline Fatty Acid & Control & ALA & ALA & $\begin{array}{c}\text { ALA } \\
(+1.4 \%\end{array}$ \\
\hline
\end{tabular}

Background diet containing ALA at $0.65 \%$ of energy

Plasma phospholipids

$20.5(n-3) \quad 0.1 \pm 0.1$

$\begin{array}{ll}20: 5(\mathrm{n}-3) & 0.1 \pm 0.1^{\mathrm{a}} \\ 22: 6(\mathrm{n}-3) & 7.1 \pm 0.2^{\mathrm{a}}\end{array}$

$0.2 \pm 0.0^{\mathrm{b}}$

$0.5 \pm 0.0^{\mathrm{bc}}$

$0.8 \pm 0.0^{\mathrm{cd}} \quad 0.9 \pm 0.0^{\mathrm{d}}$

$1.7 \pm 0.2^{\mathrm{e}}$

$3.2 \pm 0.2^{\mathrm{f}}$

$22: 6(n-3) \quad 7.1 \pm 0.2$

$6.4 \pm 0.3^{\mathrm{a}}$

$8.3 \pm 0.1^{\mathrm{b}} \quad 8.6 \pm 0.1^{\mathrm{b}}$

$8.8 \pm 0.3^{b}$

$9.0 \pm 0.5^{\mathrm{b}}$

$9.3 \pm 0.4^{\mathrm{b}}$

Erythrocyte phospholipids

$\begin{array}{llllllll}20: 5(\mathrm{n}-3) & 0.3 \pm 0.0^{\mathrm{a}} & 0.4 \pm 0.0^{\mathrm{a}} & 0.5 \pm 0.1^{\mathrm{a}} & 0.9 \pm 0.0^{\mathrm{b}} & 1.6 \pm 0.1^{\mathrm{c}} & 2.4 \pm 0.1^{\mathrm{d}} & 4.5 \pm 0.2^{\mathrm{e}} \\ 22: 6(\mathrm{n}-3) & 7.5 \pm 0.2^{\mathrm{a}} & 7.9 \pm 0.3^{\mathrm{ab}} & 8.5 \pm 0.3^{\mathrm{bc}} & 8.3 \pm 0.1^{\mathrm{bc}} & 9.1 \pm 0.5^{\mathrm{bc}} & 8.7 \pm 0.2^{\mathrm{c}} & 8.2 \pm 0.2^{\mathrm{bc}}\end{array}$

Background diet containing ALA at $1.3 \%$ of energy

Plasma phospholipids

$\begin{array}{llllllll}20: 5(\mathrm{n}-3) & 0.3 \pm 0.0^{\mathrm{a}} & 0.4 \pm 0.0^{\mathrm{ab}} & 0.6 \pm 0.0^{\mathrm{bc}} & 0.8 \pm 0.0^{\mathrm{cd}} & 0.9 \pm 0.0^{\mathrm{d}} & 1.7 \pm 0.1^{\mathrm{e}} & 3.2 \pm 0.2^{\mathrm{f}} \\ 22: 6(\mathrm{n}-3) & 8.5 \pm 0.1 & 9.9 \pm 0.4 & 9.6 \pm 0.6 & 9.4 \pm 0.2 & 9.7 \pm 0.3 & 9.7 \pm 0.3 & 9.8 \pm 0.2\end{array}$

Erythrocyte phospholipids

$\begin{array}{llllllll}20: 5(\mathrm{n}-3) & 0.5 \pm 0.0^{\mathrm{a}} & 0.6 \pm 0.0^{\mathrm{a}} & 0.8 \pm 0.0^{\mathrm{b}} & 1.0 \pm 0.0^{\mathrm{b}} & 1.5 \pm 0.0^{\mathrm{c}} & 2.8 \pm 0.0^{\mathrm{d}} & 4.8 \pm 0.2^{\mathrm{e}} \\ 22: 6(\mathrm{n}-3) & 8.2 \pm 0.0^{\mathrm{a}} & 8.6 \pm 0.1^{\mathrm{b}} & 8.7 \pm 0.2^{\mathrm{b}} & 8.8 \pm 0.1^{\mathrm{b}} & 8.6 \pm 0.1^{\mathrm{b}} & 8.6 \pm 0.1^{\mathrm{b}} & 8.5 \pm 0.1^{\mathrm{ab}}\end{array}$

All diets contained: LA (6\%en), ARA $(0.07 \%$ en), EPA+DHA $(0.1 \%$ en) and two different doses of ALA $(0.65 \%$ en and $1.3 \%$ en). The experimental diets were supplemented with ALA or EPA at three doses $(0.3 \%$ en, $0.8 \%$ en and $1.4 \%$ en) for 4 weeks. Data presented as mole $\%$ of total fatty acids (mean \pm SEM) and were compared across treatment groups using a one-way analysis of variance (ANOVA), followed by Tukey's Honestly Significant Difference (HSD) post-hoc test to determine significant differences between groups. All data were tested for normality, homogeneity of variance, and for outliers. The data were evaluated by SPSS 18 statistical package (University of Tennessee, Knoxville, TN). Different superscripts within the same row are statistically significant, $\mathrm{p}<0.05$. ALA, alpha-linolenic acid; EPA, eicosapentaenoic acid. $\mathrm{N}=4-5 /$ group.

N-6 PUFA Supplementation. When mice, on background diets that mimicked the US diet, were supplemented with LA, tissue responses for ARA were similar as that observed with humans. For example, increasing or decreasing LA has little impact on changing tissue ARA content (Table 4, Fig. 4A). Following supplementation with ARA, the changes in ARA content in mouse tissues were less responsive thanthat observed in humans when human diets were supplemented with ARA (Table 4, Fig. 4B).

\section{SUMMARY AND CONCLUSIONS}

If the interest is to only investigate the positive physiologic or mechanistic impacts of dietary PUFAs in pre-clinical models, then diets can be designed to maximize positive results following 
a dose response. For example, if the desire is to observe a positive effect with dietary LA or ALA, animals could be provided background diets devoid or depleted of PUFA [22, 23], or animals could be provided background diets devoid of n-3 PUFA (i.e., AIN76A) when investigating the effects of ALA, EPA, or DHA, and/or they could be supplemented with pharmacological (or higher) doses.

If the interest is to generate data with the intention that the results could have some translation value, the design of the diet would be much different. In general, when rodents are used in dietary experiments, they are from the same strain, the same breeding colony, are genetically similar, eat the same amount and the same food, have identical living conditions (circadian rhythm, housing), same exercise patterns, etc., while treated with pharmacological doses of the experimental nutrient. However, humans are genetically diverse, ethnically and culturally diverse, consume different diets and different amounts, have diverse living conditions (circadian rhythm, housing) and different exercise patterns, etc, yet they are provided much lower doses ("human equivalent dose"). The Western diet contains EPA, DHA, and ARA, while the major commercial rodent diets are devoid of these fatty acids. Could this be a mitigating factor when responses in humans do not match those observed in rodents?

Table 4. The effects of linoleic acid or arachidonic acid supplementation on plasma or erythrocyte n-6 PUFA composition in mice.

\begin{tabular}{|c|c|c|c|c|c|c|}
\hline \multirow{2}{*}{\multicolumn{2}{|c|}{ Fatty Acid $\quad-2 \%$ LA }} & \multirow[t]{2}{*}{ Control } & $+2 \% \mathrm{LA}$ & $+4 \% \mathrm{LA}$ & $+6 \%$ LA & \multirow[t]{2}{*}{$+8 \% \mathrm{LA}$} \\
\hline & & & & & & \\
\hline $18: 2 n-6$ & $12.5 \pm 0.5$ & $19.2 \pm 0.4^{\mathrm{ab}}$ & $20.6 \pm 0.4^{\mathrm{ab}}$ & $21.9 \pm 0.9^{b}$ & $22.2 \pm 1.5^{\mathrm{b}}$ & $22.5 \pm 1.3^{b}$ \\
\hline $20: 4 n-6$ & $13.1 \pm 0.4$ & $12.7 \pm 0.5$ & $13.9 \pm 0.8$ & $13.4 \pm 0.6$ & $11.8 \pm 0.8$ & $13.1 \pm 0.6$ \\
\hline \multicolumn{7}{|c|}{ Erythrocyte phospholipids } \\
\hline $18: 2 n-6$ & $10.7 \pm 0.1^{\mathrm{a}}$ & $12.0 \pm 0.2^{\mathrm{b}}$ & $12.2 \pm 0.2^{\mathrm{b}}$ & $13.1 \pm 0.5^{\mathrm{bc}}$ & $13.7 \pm 0.3^{\text {cd }}$ & $14.5 \pm 0.1^{\mathrm{d}}$ \\
\hline $20: 4 n-6$ & $14.3 \pm 0.5$ & $13.6 \pm 0.6$ & $14.6 \pm 0.5$ & $15.1 \pm 0.7$ & $14.6 \pm 0.4$ & $13.7 \pm 0.7$ \\
\hline Fatty Acid & Control & $+0.23 \% \mathrm{AA}$ & $+0.45 \% \mathrm{AA}$ & \multicolumn{2}{|c|}{$+1.36 \% \mathrm{AA}$} & \\
\hline \multicolumn{7}{|c|}{ Plasma phospholipids } \\
\hline $18: 2 n-6$ & $19.2 \pm 0.5^{\mathrm{a}}$ & $18.9 \pm 0.6^{\mathrm{ab}}$ & $17.0 \pm 0.3^{\mathrm{bc}}$ & \multicolumn{2}{|c|}{$15.5 \pm 0.4^{\mathrm{c}}$} & \\
\hline $20: 4 n-6$ & $12.7 \pm 0.5^{\mathrm{a}}$ & $14.2 \pm 0.7^{\mathrm{ab}}$ & $15.9 \pm 0.8^{\mathrm{bc}}$ & \multicolumn{2}{|c|}{$17.9 \pm 1.0^{\mathrm{c}}$} & \\
\hline \multicolumn{7}{|c|}{ Erythrocyte phospholipids } \\
\hline $18: 2 n-6$ & $12.0 \pm 0.3^{\mathrm{a}}$ & $10.9 \pm 0.2^{\mathrm{b}}$ & \multirow{2}{*}{$\begin{array}{l}9.7 \pm 0.2^{\mathrm{c}} \\
16.8 \pm 0.5^{\mathrm{bc}}\end{array}$} & \multicolumn{2}{|c|}{$7.8 \pm 0.1^{\mathrm{d}}$} & \\
\hline $20: 4 n-6$ & $13.6 \pm 0.6^{\mathrm{a}}$ & $15.1 \pm 0.5^{\mathrm{ab}}$ & & \multicolumn{2}{|c|}{$18.7 \pm 0.9^{\mathrm{c}}$} & \\
\hline
\end{tabular}

All diets contained: LA (6\%en), ARA (0.07\%en), ALA (0.65\%en), and EPA+DHA (0.1\%en). The experimental diets were supplemented with LA at 5 doses (minus $2 \%$ en, $2 \%$ en, $4 \%$ en, $6 \%$ en, and $8 \%$ en) or ARA at 3 doses $(0.23 \%$ en, $0.45 \%$ en, $1.36 \%$ en $)$ for 4 weeks. Data presented as mole $\%$ of total fatty acids (mean \pm SEM) and were compared across treatment groups using a one-way analysis of variance (ANOVA), followed by Tukey's Honestly Significant Difference (HSD) post-hoc test to determine significant differences between groups. All data were tested for normality, homogeneity of variance, and for outliers. The data were evaluated by SPSS 18 statistical package (University of Tennessee, Knoxville, TN). Different superscripts within the same row are statistically significant, $\mathrm{p}<0.05$. ARA, arachidonic acid; LA, linoleic acid. $\mathrm{N}=4-5 /$ group.

The objective of this review and the experiments/data presented here was to provide some guidelines for possible ways of improving the quality of data from diet-related pre-clinical experiments, if the desire is to have translatability. There are a number of mathematical models 
for allometric scaling. When comparing the extrapolation of all nutrients in a rodent diet (macroand micronutrients), extrapolation based on differences in metabolic rate was found to be most closely associated with the US DRIs, and therefore should be a seriously considered model. With regards to dietary PUFA, other factors may also be considered. There appears to be a difference in the need of DHA when moving between species of different size. Smaller mammals have a higher metabolic need for DHA in their tissues [26]. Therefore, changes in their tissue levels of LC n-3 PUFA are enhanced when their diets are supplemented with ALA or EPA even though the background diets already contain ALA, EPA, and DHA - effects not observed in humans.

Accordingly, even with the most conservative design, an exaggerated response is still possible. Doubling the ALA content in the background diet (from $0.65 \%$ en to $1.3 \%$ en) was one way of trying to better match the changes in the tissue PUFA profiles, doing so seemed to "prime" the tissues with EPA and DHA. It is unknown if this is appropriate or if this modification will help to minimize "false positive" results.

Our results show that if mice are fed a background diet that mimics the US diet and supplemented with human equivalent doses of LA, there are observable human equivalent responses with regards to changes in tissue ARA content. Consequently, it is possible to generate similar responses in rodents as observed in humans (no changes in tissue ARA content) without supplementing the background diet with ARA (which is very expensive) by providing sufficient amount of LA to the background diet [30]. It appears that while rodents have a higher need for DHA, they don't seem to have the same response to dietary ARA in changing tissue ARA levels. This may speak to need of rodents to have higher n-3 to n-6 ratios in their tissues.

On a practical note, based on the data presented here, there is a distinction that can be made between the major commercial diets given the fact that none of them contain LC PUFA (i.e., ARA, EPA and DHA). There are commercial diets that contains the nutrient distribution outlined in Table 2 (absent the ARA, EPA and DHA) at a cost equivalent to other commercial diets [31]. Regarding the AIN76A, AIN93G, and AIN93M diets, AIN76A contains no n-3 PUFA. Accordingly, animals will be fed an essential fatty acid deficient diet. Of the other two diets, AIN93G contains a higher amount of ALA $(3.8 \% \mathrm{w} / \mathrm{w}$ versus $2.2 \% \mathrm{w} / \mathrm{w}$ in the AIN93M diet). Thus, this may help to moderate an exaggerated response when additional n-3 PUFA are being added to diets. Certainly, using $\mathrm{BW}^{0.67}$ or the "formula" presented earlier appear to be almost as good as metabolic rate (Table 1), which would, in this reviewer's opinion, be adequate substitutes.

Competing Interests: The author has no financial interests or any other conflicts of interest to disclose

Acknowledgements: This work was supported by the Tennessee Agricultural Experiment Station, University of Tennessee, Knoxville, TN 37996.

\section{REFERENCES:}

1. Burr G, Burr M: A new deficiency disease produced by the rigid exclusion of fat from the diet. J Biol Chem 1929;82:345-367. 
2. Burr G, Burr M: On the nature and role of the fatty acids essential in nutrition. $\mathrm{J}$ Biol Chem 1930;86:587-621.

3. Whelan J, Hardy R, Wilkes RS, Valentin HE: Sustainable production of omega-3 fatty acids; in Songstad DD, (ed): Springer-Verlag Berlin Heidelberg, 2014, pp 129-168.

4. Whelan J, Fritsche K: Linoleic acid. Adv Nutr 2013;4:311-312.

5. Petrik MB, McEntee MF, Chiu $\mathrm{CH}$, Whelan $\mathrm{J}$ : Antagonism of arachidonic acid is linked to the antitumorigenic effect of dietary eicosapentaenoic acid in $\operatorname{Apc}(\mathrm{Min} /+)$ mice. J Nutr 2000;130:1153-1158.

6. Baum SJ, Kris-Etherton PM, Willett WC, Lichtenstein AH, Rudel LL, Maki KC, Whelan J, Ramsden CE, Block RC: Fatty acids in cardiovascular health and disease: A comprehensive update. J Clin Lipidol 2012;6:216-234.

7. Ramsden CE, Ringel A, Feldstein AE, Taha AY, MacIntosh BA, Hibbeln JR, Majchrzak-Hong SF, Faurot KR, Rapoport SI, Cheon Y, Chung YM, Berk M, Mann JD: Lowering dietary linoleic acid reduces bioactive oxidized linoleic acid metabolites in humans. Prostaglandins Leukot Essent Fatty Acids 2012;87:135-141.

8. Abel S, Riedel S, Gelderblom WC: Dietary PUFA and cancer. Proc Nutr Soc 2014;73:361-367.

9. Whelan J, McEntee MF: Dietary (n-6) PUFA and intestinal tumorigenesis. J Nutr 2004; 134:3421S-3426S.

10. Marion-Letellier R, Savoye G, Ghosh S: Polyunsaturated fatty acids and inflammation. IUBMB Life 2015;67:659-667.

11. Rucker R, Storms D: Interspecies comparisons of micronutrient requirements: metabolic vs. absolute body size. J Nutr 2002;132:2999-3000.

12. Rucker RB: Allometric scaling, metabolic body size and interspecies comparisons of basal nutritional requirements. J Anim Physiol Anim Nutr (Berl) 2007;91:148-156.

13. Kleiber M: Body size and metabolic rate. Physiol Rev 1947;27:511-541.

14. White CR, Seymour RS: Mammalian basal metabolic rate is proportional to body mass2/3. Proc Natl Acad Sci U S A 2003;100:4046-4049.

15. Reagan-Shaw S, Nihal M, Ahmad N: Dose translation from animal to human studies revisited. FASEB J 2008;22:659-661.

16. Center for Drug Evaluation and Research, Center for Biologics Evaluation and Research: Estimating the safe starting dose in clinical trials for therapeutics in adult healthy volunteers; Rockville, MD, USA, U.S. Food and Drug Administration, 2002.

17. Freireich EJ, Gehan EA, Rall DP, Schmidt LH, Skipper HE: Quantitative comparison of toxicity of anticancer agents in mouse, rat, hamster, dog, monkey, and man. Cancer Chemother Rep 1966;50:219-244.

18. Rucker RB, Steinberg FM: Vitamin Requirements: relationship to basal metabolic need and function. Biochem Molec Biol Educ 2002;30:86-89.

19. Institute of Medicine: Dietary reference intakes for energy, carbohydrate, fat, fatty acids, cholesterol, protein, and amino acids; Washington, DC, The National Academies Press, 2005.

20. Reeves PG, Nielsen FH, Fahey GC, Jr.: AIN-93 purified diets for laboratory rodents: final report of the American Institute of Nutrition ad hoc writing committee on the reformulation of the AIN-76A rodent diet. J Nutr 1993;123:1939-1951. 
21. Reeves PG: Components of the AIN-93 diets as improvements in the AIN-76A diet. J Nutr 1997; 127:838S-841S.

22. Mohrhauer H, Holman RT: The effect of dietary essential fatty acids upon composition of polyunsaturated fatty acids in depot fat and erythrocytes of the rat. $\mathrm{J}$ Lipid Res 1963;4:346-350.

23. Mohrhauer H, Holman RT: The effect of dose level of essential fatty acids upon fatty acid composition of the rat liver. J Lipid Res 1963;4:151-159.

24. Mohrhauer H, Holman RT: Effect of linolenic acid upon the metabolism of linoleic acid. J Nutr 1963;81:67-74.

25. Kris-Etherton PM, Harris WS, Appel LJ: Fish consumption, fish oil, omega-3 fatty acids, and cardiovascular disease. Circulation 2002;106:2747-2757.

26. Hulbert AJ, Rana T, Couture P: The acyl composition of mammalian phospholipids: an allometric analysis. Comp Biochem Physiol B Biochem Mol Biol 2002;132:515527.

27. Rett BS, Whelan J: Increasing dietary linoleic acid does not increase tissue arachidonic acid content in adults consuming Western-type diets: a systematic review. Nutr Metab (Lond) 2011;8:36.

28. Arterburn LM, Hall EB, Oken H: Distribution, interconversion, and dose response of n-3 fatty acids in humans. Am J Clin Nutr 2006;83:1467S-1476S.

29. Taber L, Chiu CH, Whelan J: Assessment of the arachidonic acid content in foods commonly consumed in the American diet. Lipids 1998;33:1151-1157.

30. Whelan J, Surette ME, Hardard'ottir I, Lu G-P, Golemboski KA, Larsen E, Kinsella JE: Dietary arachidonate enhances tissue arachidonate levels and eicosanoid production in Syrian hamsters. J Nutr 1993;123:2174-2185.

31. Weldon KA, Whelan J: Allometric scaling of dietary linoleic acid on changes in tissue arachidonic acid using human equivalent diets in mice. Nutr Metab (Lond) 2011;8:43.

32. Petrik MB, McEntee MF, Johnson BT, Obukowicz MG, Whelan J: Highly unsaturated (n-3) fatty acids, but not alpha-linolenic, conjugated linoleic or gamma-linolenic acids, reduce tumorigenesis in Apc(Min/+) mice. J Nutr 2000;130:2434-2443.

33. Whelan J, Jahns L, Kavanagh K: Docosahexaenoic acid: measurements in food and dietary exposure. Prostaglandins Leukot Essent Fatty Acids 2009;81:133-136. 